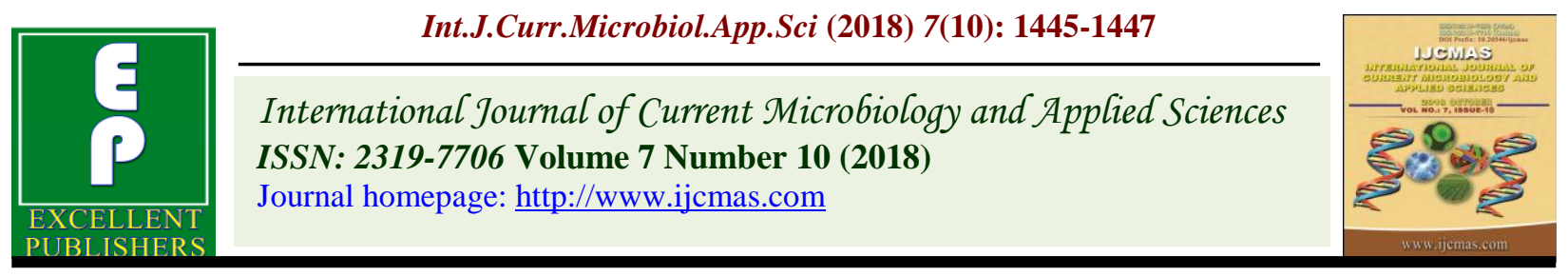

Case Study

https://doi.org/10.20546/ijcmas.2018.710.160

\title{
Closantel Intoxication in a Sheep: Case Study
}

\author{
Neha Rao*, J.J. Parmar, D.B. Sadhu, A.I. Shah and D.M. Patel \\ Veterinary Clinical Complex, College of Veterinary Science and Animal Husbandry, Anand \\ Agricultural University, Anand-188001, Gujarat, India \\ *Corresponding author
}

\begin{tabular}{|l|l}
\hline \multicolumn{1}{c}{ A B S T R A C T } \\
\cline { 1 - 1 } $\begin{array}{l}\text { Key words } \\
\begin{array}{l}\text { Closantel, Sheep, } \\
\text { Intoxication }\end{array}\end{array}$ & $\begin{array}{l}\text { Salicylanilides are very large group of compounds originally developed as fungicides for } \\
\text { topical use and as antimicrobial agents in soaps which also possess potent anthelmintic } \\
\text { activity. Closantel and rafoxanide are important anthelmintics used extensively to control } \\
\text { Haemonchus spp. and Fasciola spp. infestation in ruminants in many parts of the world } \\
\text { (Swan, 1999). Toxicity of Closantel has been reported in many species including dogs } \\
\text { (McEntee, 1995), sheep and goat (Lunt and Venter, 2007) and in human (Tabatabaei } \text { et al., } \\
\text { Article Info }\end{array}$ \\
$\begin{array}{l}\text { 2016). This paper presents Closantel intoxication with its clinical findings and outcome in } \\
\text { 15 September 2018 } \\
\text { Available Online: } \\
\text { 10 October 2018 }\end{array}$ & \\
\hline
\end{tabular}

\section{Case history and observations}

Two male sheep of three year age weighing 36 and $39 \mathrm{~kg}$ from a same flock were presented to Veterinary Clinical Complex with complaint of sudden vision loss for the last three days. Anamnesis revealed that ten days back owner drenched the sheep with $15 \mathrm{ml} 15 \%$ solution of Closantel and after three days of drenching blindness was noticed in both the animals without affecting appetite. The clinical examinations revealed animals were active with no neurological derangement.

Physiological and haematological parameters were within normalrange. Complete bilateral vision loss with dilated pupils (Fig. 1) was noted. Detailed ophthalmic examination revealed menace and pupillary light reflex were negative with mydriasis of both the eyes. Intraocular pressure measurements were also within normal range. Ultrasonographic examination revealed no any abnormal changes. Slit lamp biomicroscopy and indirect ophthalmoscopy revealed normal tepetal and non tepetal differentiation, normal optic disc with prominent blood vessels (Fig. 2).

\section{Treatment and Discussion}

Both the sheep were treated with nervine tonic injection as a neuroprotectant and Inj. Dexamethasone@2mg/kg body weight followed by Eye drops (Brimonidine tartrate) topically twice a day. This was followed by oral nervine tonic for 10 days. Both the animals were advised to be kept under close observations for up to two months. 
Fig.1 Dilated pupil

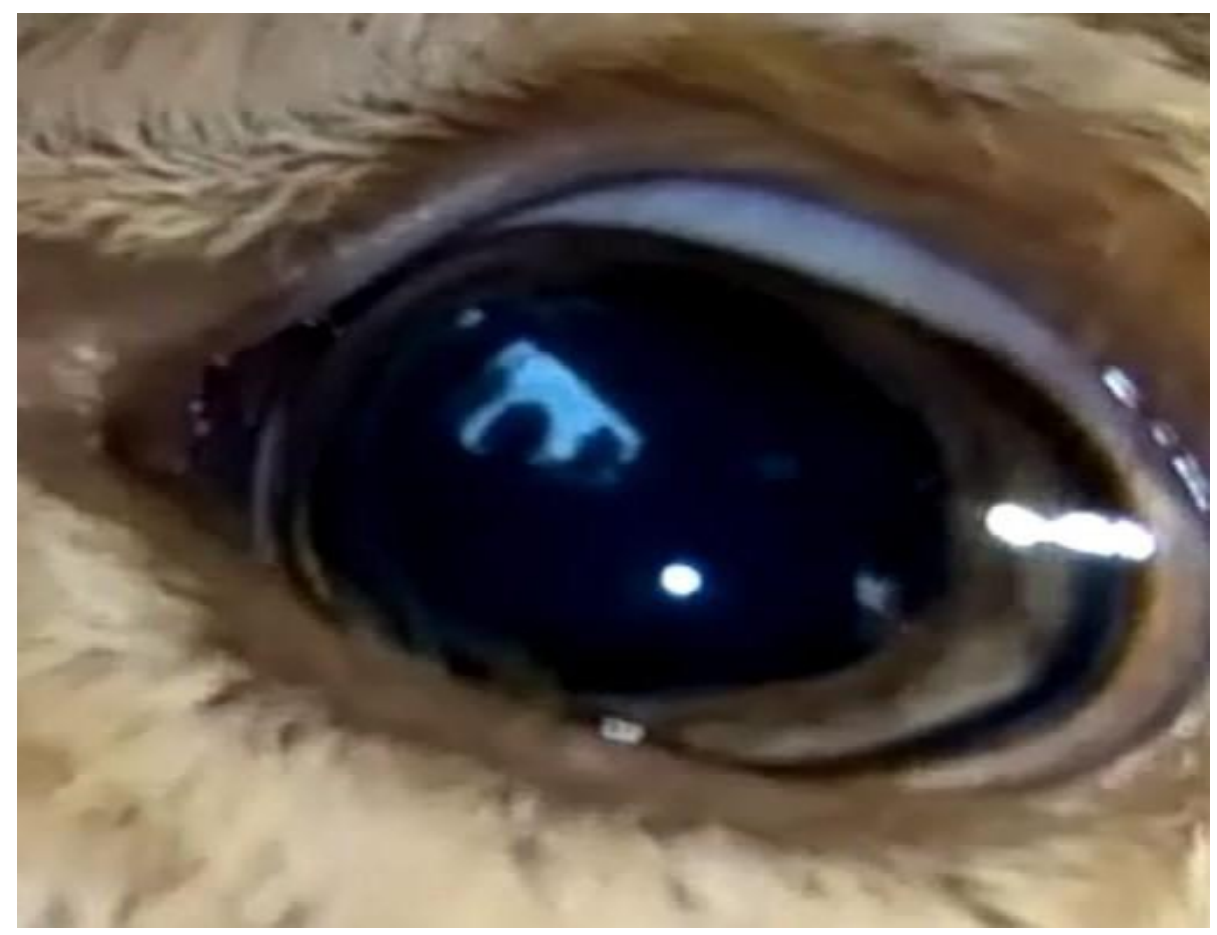

Fig.2 Indirect ophthalmoscopy

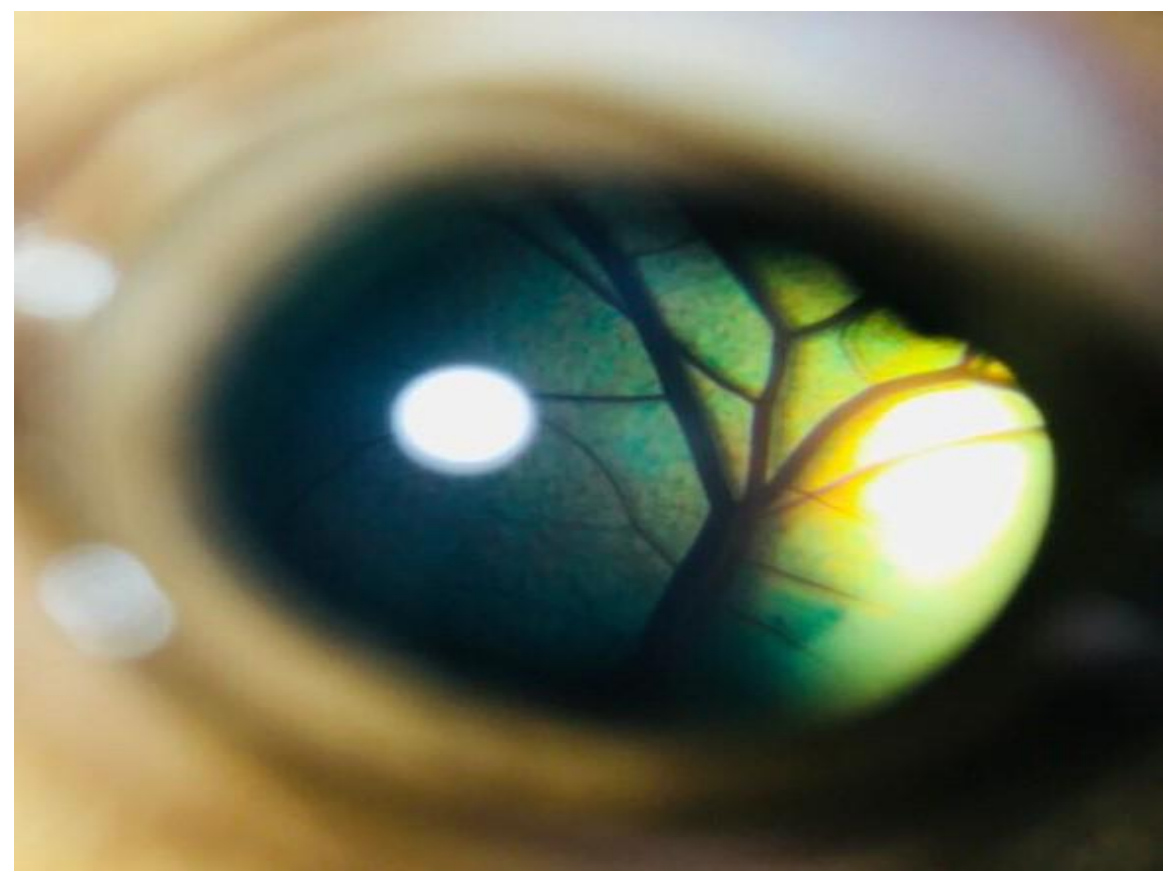

Mortality was not reported but complete blindness of both eyes was found in both the animals.
Accidental poisoning occurs when a drug get ingested at a rate 2-6 times higher than recommended dose (Rivero et al., 2015). 
There are several reports describing the toxicity of Closantel in animals and the clinical signs of Closantel toxicity in sheep included in appetence, blindness, mydriasis and ophthalmoscopic papilloedema (Swan, 1999). Effects of Closantel on brain, spinal cord, retina and optic disc have been detected (Prozesky and Pienaar, 1977).

Sakhaeea and Derakhshanfar (2010) reported blindness, depression, head pressing, circling, teeth grinding, incoordination, ataxia, depression of the palpebral and pupillary reflexes, nystagmus, dilated pupils, muscle tremors, frothy salivation and recumbency with opisthotonus, extension of the limbs, hyperaesthesia and periodic tonic-clonic convulsions whereas in our study only blindness was observed with no other neurological symptoms.

Our observations were similar to Tiwari et al., (2007) reported only blindness without other neurological symptoms in goats after ingestion of $10 \mathrm{ml}$ Closantel and treatment with vitamin preparations with no desirable improvement in condition. In our study animals were treated with neuro vitamins as a neuro protectant and corticosteroids followed by oral nervine tonic along with topical eye drop for 10 days but there was no any improvement in vision.

There is no any specific antidote to reversing Closantel toxicity. Hence Closantel toxicity in animals needs to be studied for future research due to its use in Veterinary practice particularly in meat animals for human consumption.

\section{References}

McEntee, K., Grauwels, M., Clercx, C., Henroteaux, M. (1995). Closantel intoxication in a dog. Veterinary and Human Toxicology, 37(3):234-236.

Prozesky, L. and Pienaar, J. G. (1977). Amaurosis in Sheep resulting from treatment with rafoxanide. Onderstepoort J. vet. Res., 44 (4), 257 260.

Rivero, R., Matto, C., Soares, M. P. and Adrien, M. L. (2015). Accidental and experimental Closantel intoxication in Uruguayan sheep. Pesq. Vet. Bras., 35(7): 599-604, julho 2015 DOI: 10.1590/S0100-736X201500070000.

Sakhaeea, E and Derakhshanfar, A. (2010). Polioencephalomalacia associated with closantel overdosage in a goat. 00382809 Tydskr.S.Afr.vet.Ver., 81(2): 116117.

Swan, G. E. (1999). The pharmacology of halogenated salicylanilides and their anthelmintic use in animals. 0038-2809 Tydskr.S.Afr.Vet.Ver., 70(2): 61-70.

Tabatabaei, S. A., Soleimani, M., Mansouri, M. R., Mirshahi, A., Inanlou, B., Abrishami, M., Pakrah, A. R. and Masarat, H. (2016). Closantel; a veterinary drug with potential severe morbidity in humans. $B M C$ Ophthalmology, 16:207.DOI 10.1186/s12886-016-0387-x.

Van der Lugt, J. J. and Venter, I. (2007). Myelin vacuolation, optic neuropathy and retinal degeneration after closantel overdosage in sheep and in a goat. $J$ Comp Pathol, 136(2-3):87-95.

\section{How to cite this article:}

Neha Rao, J.J. Parmar, D.B. Sadhu, A.I. Shah and Patel, D.M. 2018. Closantel Intoxication in a Sheep: Case Study. Int.J.Curr.Microbiol.App.Sci. 7(10): 1445-1447. doi: https://doi.org/10.20546/ijcmas.2018.710.160 